\title{
Irradiation for Mold and Mycotoxin Control: A Review
}

\author{
Thalita Calado, Armando Venâncio, and Luís Abrunhosa
}

\begin{abstract}
The mycotoxin issue requires constant vigilance from economic, regulatory, and scientific agents to minimize its toxicological effects on human and animals. The implementation of good practices to avoid fungal growth and mycotoxin production on agricultural commodities is essential to achieve most restrictive safety standards; however, the contribution of novel technologies that may act on postharvesting and poststorage situations may be equally important. Several methodologies, more or less technologically advanced, may be used for this purpose. In this work, we review the role, contribution, and impact of irradiation technology to control the presence of fungi and mycotoxins in food and in feed. The effect of this technology on the viability of mold spores and on the elimination of mycotoxins is reviewed. A critical evaluation of the advantages and disadvantages of irradiation in this context is presented.
\end{abstract}

Keywords: feed, food, fungi, irradiation, mycotoxins

\section{Introduction}

The constant demand of consumers for safer, "healthier," and processed food drives the development of technologies in food processing to achieve their needs. Food safety is one of the major challenges for technology, although many preservation processes and regulations are already available to control the microbiological and chemical integrity of food. Food irradiation is one among many of available technologies that contribute to improve the safety of food.

Food irradiation is a physical method of food processing that involves exposing prepackaged or bulk foodstuffs to ionizing energy. This process is sometimes called "cold pasteurization" because the inactivation of microorganisms is achieved at low temperatures unlike the traditional heat pasteurization. Using irradiation, the microbiological safety of food can be improved and its shelf-life prolonged without substantially changing, in most cases, its nutritional, chemical, and physical properties. The elimination of pests on agricultural commodities can also be achieved, thus reducing food losses and the use of chemical fumigants and additives. Food irradiation up to an overall dose of $10 \mathrm{kGy}$ has been considered a safe and effective technology since 1981 by several international food organizations (FAO/IAEA/WHO 1981). Later on, doses above $10 \mathrm{kGy}$ were also considered safe for some niche products and markets (FAO/IAEA/WHO 1999). Nonetheless, food irradiation is not as widespread as other conventional technologies due to the high costs of irradiation units and, particularly, because of a negative perception of consumers relatively to its safety.

MS 20140621 Submitted 14/4/2014, Accepted 23/5/2014. Authors are with CEB - Centre of Biological Engineering, Univ. of Minho, Campus de Gualtar, 4710-057, Braga, Portugal. Direct inquiries to author Abrunhosa (E-mail: luisjap@deb.uminho.pt).

\section{The Food Irradiation Technology \\ Principles of radiation}

Radiation is energy that originates from a source and that travels through most materials and through space. Light, heat, and sound are types of radiation (Satin 1996). Radiation is commonly classified according to wave frequency, for example, radio wave, microwave, infrared, visible light, ultraviolet radiation, X-rays, and $\gamma$-rays (Figure 1). The electromagnetic spectrum is also divided into 2 types of radiation: nonionizing radiation and ionizing radiation. The radiation discussed in this article is of the ionizing type. Ionizing radiation is produced by unstable atoms that have an excess of energy or mass or both and that reach stability by giving off these atoms or by emitting the excess energy or mass that these atoms possess.

The irradiation of food is a process where food is exposed to ionizing energy, such as $\gamma$ photons emitted by ${ }^{60} \mathrm{Co}$ (or infrequently by ${ }^{137} \mathrm{Cs}$ ) radioisotopes, $\mathrm{X}$-rays generated by machines operated below a nominal energy of $5 \mathrm{MeV}$, and accelerated electrons generated by machines operated below a nominal energy of $10 \mathrm{MeV}$ (Farkas and Mohácsi-Farkas 2011). Only these sources can be used for food irradiation because energies emitted by these sources are much too low to induce radioactivity in any exposed material.

Food irradiation using ${ }^{60} \mathrm{Co}$ is presently the preferred method because this method has a deep penetration capacity that enables the treatment of materials with less handling. Nonetheless, irradiators using ${ }^{60} \mathrm{Co}$ must be recalibrated on a monthly basis because of the continuing decay and concomitant loss of radioactive energy of this isotope (Prado 2005). Gamma-radiation can also be achieved by an isotope of cesium $\left({ }^{137} \mathrm{Cs}\right)$. In this case, this material is obtained by reprocessing and by extracting spent nuclear fuel from nuclear reactors. This fact has brought much criticism from nuclear opponents who claim that food irradiation was simply invented to 


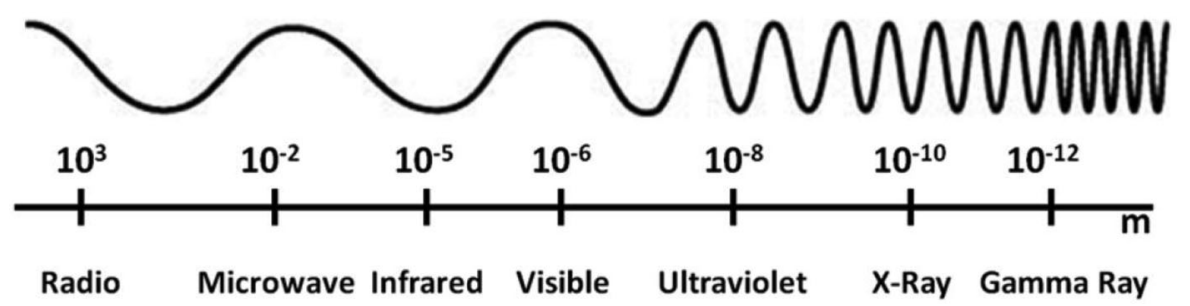

Figure 1-The electromagnetic spectrum (adapted from Satin 1996).

eliminate nuclear waste (Satin 1996). As a result, ${ }^{137} \mathrm{Cs}$ irradiators represent an extremely small proportion of today's irradiators. In contrast, the utilization of X-rays and electron beams involves the use of electrical machine sources of energy. An obvious advantage of such systems is that these systems can be switched on and off, similar to a light bulb, and are in no way related to the nuclear industry (Satin 1996). X-rays have low energetic efficiency, given that only $3 \%$ to $5 \%$ of the energy is converted to radiation, and electron beams have a limited penetration ability (Prado 2005). Typically, the penetration power of electron beams is only suitable for materials with a thickness of no more than 5 to $10 \mathrm{~cm}$ (Satin 1996). However, for certain uses, electron beams have proven to be extremely practical primarily for treating food surfaces, meat, and fruits.

\section{Mechanism of action}

Living cells are inactivated when exposed to factors that substantially change their cellular structure or physiological functions. Lethal structural damages include DNA strand breakage, cell membrane rupture, or mechanical damage to cell walls (Lado and Yousef 2002). During the irradiation of food, DNA is strongly damaged by radiation; therefore, primarily by this mechanism, microorganisms, insect gametes, and plant meristems are prevented from reproducing (Farkas 2006). DNA damage may result from a direct action of the ionizing radiation or from an indirect action of the oxidative radicals that originated from the radiolysis of cellular water (Farkas 2006).

The radiolysis of water takes approximately $10^{-6} \mathrm{~s}$ to occur. When water is irradiated by ionizing radiation, water molecules undergo a breakdown sequence that forms several radiolysis products that are extremely reactive with other chemical substances (Figure 2). The primary reactions that occur are the ionization and excitation of water molecules. Ionization causes the splitting of water molecules into positively charged water radicals $\left(\mathrm{H}_{2} \mathrm{O}^{+}\right)$ and negative free solvated electrons $\left(\mathrm{e}^{-}\right)$; at the end of the process, due to various recombination and cross-combination reactions, the following reactive species are present: $\mathrm{e}^{-}$aq $, \mathrm{H}^{\circ}, \mathrm{HO}^{\circ}, \mathrm{HO}_{2}{ }^{\circ}$, $\mathrm{OH}^{-}, \mathrm{H}_{3} \mathrm{O}^{+}, \mathrm{H}_{2}$, and $\mathrm{H}_{2} \mathrm{O}_{2}$ (Le Caër 2011).

Thus, these reactive species are free to react with any component present in the cell cytoplasm. The hydroxyl radicals remove hydrogen atoms from sugar and from the 4 bases of DNA strands (Lado and Yousef 2002). The other free radicals will also attack and break down organic molecules (Stepanik and others 2007). Potentially lethal DNA lesions are randomly scattered throughout the cell population during ionizing. The cells that are unable to repair their radiation-damaged DNA die (Lado and Yousef 2002). Differences in radiation sensitivities among microorganisms are related to differences in their chemical and physical structures and in their ability to recover from radiation injury (Farkas 2006). In general, the sensitivity of organisms to radiation increases with their complexity. Thus, the required radiation doses to achieve effective inactivation usually increase as follows: insects $<$ parasites $<$ molds and yeasts < vegetative (nonspore-forming) bacteria $<$ spore-forming bacteria $<$ viruses. Therefore, viruses are the most resistant to destruction by irradiation, and insects and parasites are the most sensitive. Moreover, spores (from bacteria and fungi) and cysts (from protozoa and parasites) are quite resistant to the effects of irradiation because spores and cysts contain very little DNA and are in highly stable resting states (Shea 2000). Therefore, the radiation energy required to control microorganisms on or in food varies according to the type of species to be eliminated, according to their population numbers and according to their developmental state. Other factors, such as the composition and moisture content of food, the fresh or frozen state of food, the temperature, and level of oxygen present during irradiation, may also influence the resistance of microorganisms to radiation, particularly in the case of vegetative cells (Farkas 2006).

Notably, during the irradiation of microorganisms, sublethally injured cells are often subject to mutations, and this occurrence can be dangerous. Mutations can result in greater, less, or similar levels of virulence or pathogenicity from parent organisms. The induction of radiation-resistant microbial populations occurred when cultures were experimentally exposed to repeated cycles of radiation (Shea 2000). However, mutations in microorganisms develop with any form of food processing (including ultraviolet light, heat, and drying). For this reason, it is extremely important to define safe irradiation doses to completely inactivate microorganisms (Shea 2000). One parameter most often used to compare the susceptibility of microorganisms to irradiation is the $D_{10}$ value, namely, the dose required to inactivate $90 \%$ of a microbial population.

\section{Nutritional and organoleptic adequacy}

All forms of food processing affect nutritional and organoleptic properties, and irradiation is no exception. At doses below $1 \mathrm{kGy}$, the nutritional losses are considered insignificant. In contrast, the irradiation of food much above $10 \mathrm{kGy}$ degrades nutrients similar to thermal processes, such as cooking, canning, pasteurizing, or blanching (Shea 2000).

Vitamin loss is the largest nutritional concern associated with food irradiation, particularly when synergism between irradiation and heat (cooking) occurs. Additionally, avitaminosis may arise when the irradiated commodity represents a large proportion of the dietary source of an essential vitamin (Shea 2000; Wood and Bruhn 2000). Water-soluble vitamins, such as the B vitamins and vitamin $\mathrm{C}$, are the most affected because these vitamins are oxidized during irradiation (Shea 2000). Nonetheless, the loss of heat-sensitive vitamins with irradiation is considered no greater than that with conventional heat-processing and is often less. In 


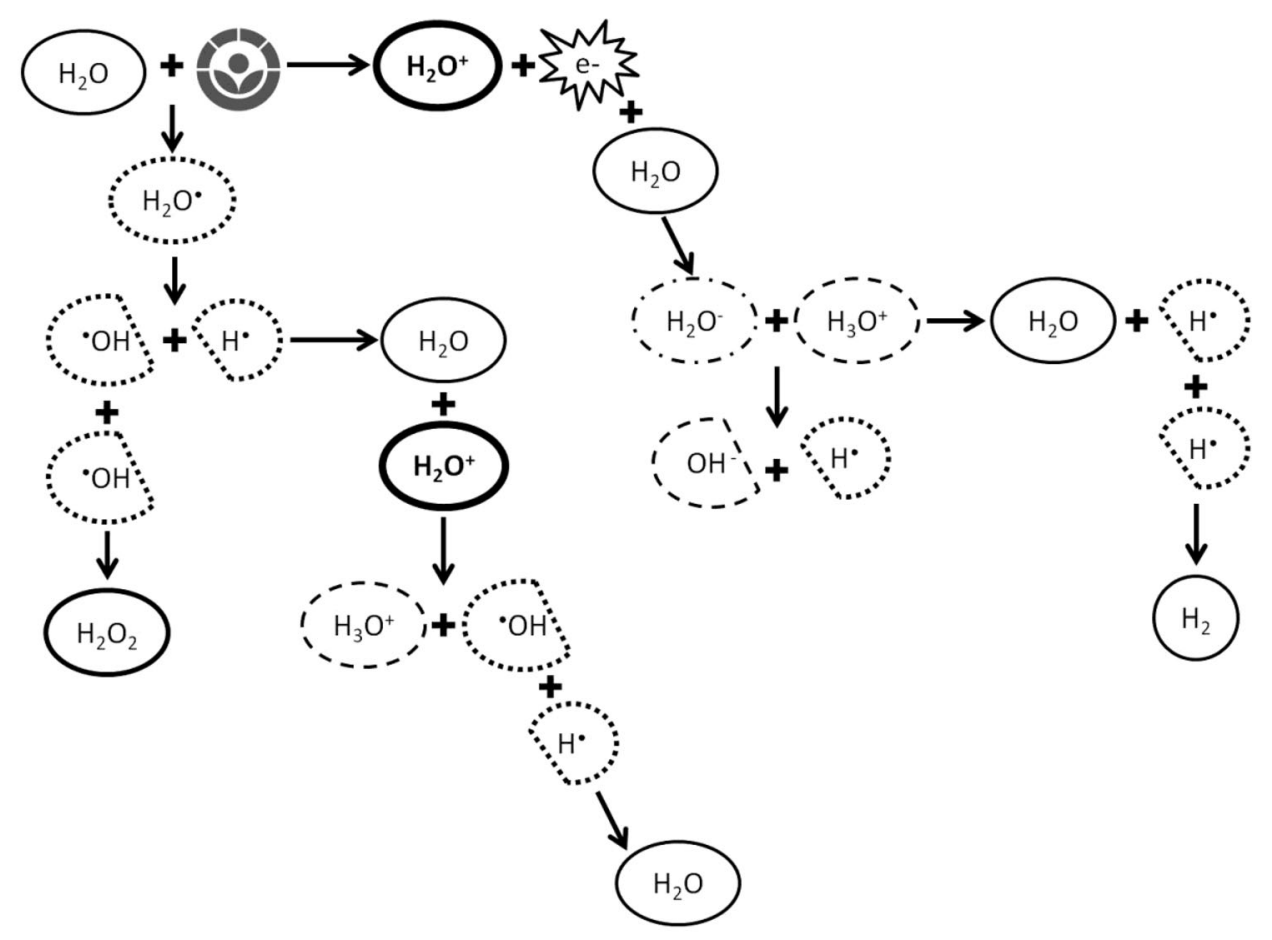

Figure 2-Reactions occurring during water radiolysis (adapted from de Campos and others 2004).

addition, research indicates that vitamin losses can be minimized by irradiating in oxygen-free packaging or at cryogenic temperatures ranging from -20 to $-40{ }^{\circ} \mathrm{C}$ (EC 2003).

Carbohydrates are not significantly affected during irradiation at less than $10 \mathrm{kGy}$ (Aziz and Mahrous 2004). In contrast to other preservation methods (such as pasteurization), protein denaturation is also not significant (Lado and Yousef 2002). A change in the bioavailability or quantity of minerals or trace elements has not been identified as a result of irradiation. Fats can be oxidized, leading to rancidity and to odor or color changes. In contrast, polyunsaturated fatty acids are not generally altered at low to medium irradiation doses (Shea 2000; Wood and Bruhn 2000). In addition to nutritional adequacy, organoleptic factors are also extremely important to the feasibility of food irradiation, particularly on fresh fruits and vegetables, which has been reviewed by Arvanitoyannis and others (2009).

\section{Safety and legislative aspects}

Food irradiation is not as widespread as other conventional technologies due to the high costs of irradiation units and, in particular, because of its unwarranted association with nuclear radiation, which gives consumers a negative perception of its safety. As a result, the health and safety of irradiated foods have been more exhaustively studied than any other processed food (Satin 1996). Since 1964, numerous international expert groups, which were jointly set up by the FAO, IAEA, WHO, and by the governments of different countries, collected and reviewed the scientific data produced over the years to consider the question of the wholesomeness of irradiated foods. The first international safety recommendation was presented in 1981, when a committee of experts considered that "... the irradiation of food up to an overall average dose of $10 \mathrm{kGy}$ introduces no special nutritional or microbiological problems" (FAO/IAEA/WHO 1981). Then, the FAO/WHO Codex Alimentarius Commission developed the Codex General Standard for Irradiated Foods and the Code of Practice for Radiation Processing of Food (Codex 2003a,2003b). These documents became widely adopted internationally and, today, specific applications of food irradiation are approved by national legislations in over 55 countries worldwide (Farkas and Mohácsi-Farkas 2011).

Regarding the European Union, the implementation of food irradiation is far less developed when compared with other countries, such as the U.S.A., Brazil, or even China. In 2005, the European region represented only $4 \%$ of the world production of irradiated food (Kume and others 2009). This situation is primarily caused by the restrictive legislation in use. Directive 1999/2/EC, concerning the "approximation of the laws of the member states concerning food and food ingredients to be treated by ionizing radiation," and Directive 1999/3/EC, concerning "the establishment of a community list of foods and food ingredients treated with ionizing," are the main legislation pieces concerning food irradiation in the European community. In the first document, the European Parliament and the Council adopted a framework directive on the general and technical aspects of food and food ingredients treated with ionizing radiation (EU 1999a). In the second document, legislators established a list of foodstuffs authorized for irradiation treatment (EU 1999b). This list of foodstuffs is composed of 3 items: "dried aromatic herbs, spices and vegetable seasonings," and the permitted maximum overall average absorbed dose is $10 \mathrm{kGy}$. Since 2009, 7 EU Member States have issued authorizations to maintain their national regulation for food products, such as fruits and vegetables, including root vegetables; cereals, cereal flakes, and rice flour; spices and condiments; fish, shellfish; fresh meats, poultry, and frog legs; raw milk camembert; gum arabic, casein/caseinates, and egg white; and blood products (EU 2009). 


\section{Applications}

From a practical point of view, 3 dose/application categories are typically considered when ionizing radiation is used to treat food: (i) a low dose of up to $1 \mathrm{kGy}$, which is used for sprout inhibition and to delay ripening and/or insect disinfestations; (ii) a medium dose from 1 to $10 \mathrm{kGy}$, which is used to reduce spoilage microorganisms, nonspore-forming pathogens, and/or to delay ripening; and (iii) a high dose from 10 to $50 \mathrm{kGy}$, which is used to eliminate microorganisms to the point of sterility for very specific products (Satin 1996).

Five groups are most often discussed when considering the type of application and of food irradiated. These 5 groups include the following: the disinfection of spices and dry vegetables, which represents $46 \%$ of all the irradiated products in the world; the sprout inhibition of garlic and potatoes, which represents $22 \%$; disinfestations of grains and of fruits, which represent $20 \%$; the disinfection of meat and seafood, which represents $8 \%$; and the treatment of other food items, such as health foods, mushrooms, or honey, which represents 4\% (Kume and others 2009). The total quantity of food irradiated in the world in 2005 was approximately 405000 metric tons.

Irradiation is also used to eliminate or to reduce the presence of pathogenic microorganisms, such as Aeromonas hydrophila, Arcobacter butzleri, Campylobacter jejuni, Listeria monocytogenes, Salmonella spp., Staphylococcus aureus, Escherichia coli O157:H7, Yersinia enterocolitica, yeasts, molds, and others, in several food matrixes (Farkas 1998, Stefanova and others 2010).

\section{Advantages and disadvantages}

The primary advantage of food irradiation is most likely the nonresidual feature of the process. In contrast to chemical methods, which leave residual components that may have or are suspected to have a negative impact on human health, irradiation is free of chemical residues. An example is the quarantine treatments required to mitigate pests from fruits, vegetables, and other plant-derived materials (Ferrier 2010). Irradiation is an excellent substitute for the conventional fumigation in use. Additional advantages of irradiation technology include: the possibility (i) of irradiating packed food at its fresh and frozen state; (ii) of controlling the hygienic quality of food by eliminating pathogenic and nonpathogenic microorganisms, insects, and parasites; (iii) of extending the shelf life of foods, thus increasing its supply, and (iv) of preserving the fresh-like quality of agricultural commodities because irradiation technology is a cold-processing method (Stefanova and others 2010). Furthermore, irradiation may be considered environment friendly because this method does not consume water and has lower electrical energy demands than other food preservative methods, with exception of electron beam and X-ray radiation, which are energy costly.

Concerning the disadvantages of this method, first, irradiation cannot be applied to all types of foods. Some fruits, such as pears and plums, vegetables, milk, and dairy products are untreatable by irradiation because these products lose firmness and some important sensory and other quality properties (Stefanova and others 2010). In other cases, irradiation can originate minor changes in the nutritional and organoleptic characteristics of treated foods as mentioned above. Most relevant for foods is the reduction of water- and fat-soluble vitamin contents; the production of off-flavors, lipid oxidation, and changes in color; the creation of oxidation compounds, such as aldehydes, ketones, and alcohols; and the formation of radiolytic products, particularly 2 alkylcyclobutanones, which are suspected to be toxic (Stefanova and others 2010). Nonetheless, most of these changes are also induced by traditional food preservative methods, such as cooking, canning, pickling, freezing, and drying. In addition, radiolytic products, such as 2-alkylcyclobutanones, have also been found on nonirradiated food products, contradicting previous beliefs (Variyar and others 2008).

The fact that food irradiation can cause the mutation of pathogenic microorganisms and could create new resistant strains can also be perceived as a disadvantage. However, the risks posed by this occurrence are minimal and comparable with those posed by other food processing methods (Farkas 1989). A further disadvantage of food irradiation is that this method can be globally more expensive than other preservative methods due to the upfront costs of food irradiation facilities. The poor acceptance of these products by consumers because of unwarranted fears that associate food irradiation with nuclear technology is also an opposing threat. Nevertheless, consumers' trust of this technology can be changed through education, provided that stakeholders disseminate conscious and scientifically rigorous information concerning the subject.

\section{Irradiation to Control Mold Growth and Mycotoxins The mold and mycotoxin issue}

Filamentous fungi are a large group of eukaryotic microorganisms that are associated with an enormous diversity of habitats. Many of them are saprophytes, which are responsible for the deterioration of agricultural products and food. Saprophytes may be responsible for the decay of commodities at a preharvest level; however, saprophytes may also be responsible for the deterioration of fresh and processed foods, causing their rejection due to the visible development of molds on these foods. In addition, some specific fungal species growing on agricultural commodities may produce mycotoxins. Mycotoxins are a hidden aspect of mold contamination because they remain on or in products well beyond the life cycle of the fungi. Moreover, mycotoxins are extremely stable and moderately heat-resistant compounds that remain almost intact after food processing (Bullerman and Bianchini 2007).

Mycotoxins are fungal secondary metabolites found in many plant foodstuffs, particularly in cereals, fruits, nuts, kernels, seeds, and animal fodder, and are toxic for humans and animals when ingested or inhaled with dust. The most relevant mycotoxins for food safety are aflatoxins (AFs), ochratoxin A (OTA), patulin, fumonisins, zearalenone (ZEN), and trichothecenes. These mycotoxins are produced by some species from the genera Aspergillus, Penicillium, and Fusarium and have multiple and combined toxic characteristics. These mycotoxins may be carcinogenic, mutagenic, teratogenic, cytotoxic, neurotoxic, nephrotoxic, immunosuppressive, and/or estrogenic (Paterson and Lima 2010).

Typically, AFs are the most well-recognized and studied mycotoxin. AFs are highly carcinogenic and hepatotoxic (Williams and others 2004) and are primarily found in peanuts, maize, nuts, spices, and in milk (where this mycotoxin occurs from the B form in feed to the AF $M$ form). OTA is primarily known for its nephrotoxicity; however, OTA is also carcinogenic to experimental animals (Pfohl-Leszkowicz and Manderville 2007). OTA is mostly found in cereals and in cereal-based products; however, OTA also occurs in coffee beans, nuts, spices, raisins, and in red wine (Jørgensen 2005). Patulin is primarily associated with fresh fruits and vegetables. Apples, apple juices, and purees are the main dietary sources of this mycotoxin. Patulin is neurotoxic, immunosuppressive, genotoxic, and teratogenic (Moake and others 2005). Fumonisins, which primarily occur in maize and in maize-based 
food products, appear to be related to an increased incidence of esophageal cancer and liver cancer in humans and are experimentally associated with leukoencephalomalacia in horses and with pulmonary edema syndrome in pigs (Voss and others 2007). ZEN is estrogenic and interferes with the reproductive system of animals, even if ZEN has a relatively low acute toxicity (Zinedine and others 2007). Similar to fumonisins, ZEN is primarily associated with maize and with maize-based food products. Trichothecenes are a large group of structurally related compounds. The most relevant trichothecenes for food safety include T-2 toxin, HT2 toxin, deoxynivalenol (DON), 3- and 15-acetyldeoxynivaleno (ADON), and nivalenol (NIV) (Foroud and Eudes 2009). These compounds are primarily found in cereal grains and are extremely cytotoxic to mammalian cells, initiating a wide range of toxic effects, such as digestive disorders, followed by diarrhea and by vomiting (Foroud and Eudes 2009).

Therefore, if the presence of mycotoxins in food and feed is not properly controlled, mycotoxins may pose important risks to public health. At low levels, mycotoxins may cause the suppression of immune functions and decrease resistance to infections in individuals. In acute situations, mycotoxins may cause the development of tumors and of chronic diseases in vital organs, or high morbidity and premature death among humans and animals (Peraica and others 1999). Additionally, mycotoxins are also responsible for major economic losses at all levels of the food-production chain. These losses are primarily associated with the rejection and destruction of contaminated materials and with expenses incurred toward the implementation of good postharvested storage conditions, analyses, and treatments to guarantee low levels of mycotoxins.

To avoid the introduction of most contaminated products into the food chain, the presence of mycotoxins in certain agricultural commodities and finished foods and feeds are regulated by statutory levels in many countries of the world (van Egmond and others 2007). Additionally, a great diversity of preventive and corrective measures can be applied to control the problem. The preventive measures may include HACCP integrated systems, which involve strategies for prevention at pre- and postharvested levels, good manufacturing practices, and quality control. The corrective measures include several physical, chemical, and biological decontamination techniques that promote the elimination of the contaminated fraction or that counteract the toxic effects of mycotoxins (Stoev 2013). Next, we will review how food irradiation can contribute to this purpose.

\section{Irradiation to control mold growth}

As already observed, molds are one of the main causes of postharvest decay problems. The presence of molds in food may result in not only a reduction in quality and in quantity but also contamination with mycotoxins, causing important health problems. Irradiation can be used for the direct purpose of eliminating or of reducing the presence of molds and mold spores in foods and in feeds, improving their shelf life and safety. Nonetheless, the application of this technology for other purposes can indirectly aid in the control of contamination with molds and, subsequently, with mycotoxins. For example, it is well known that grains damaged by insects are more susceptible to mold development and to mycotoxin accumulation because insects carry fungal spores and compromise the integrity of grains and plant tissues, facilitating the penetration and access to nutrients of fungal hyphae and, by consequence, fungal development (Jouany 2007). Thus, the elimination of insect pests from agricultural commodities through irradiation can indirectly have a positive preventing effect on the reduction of fungal contamination and mycotoxin levels in treated commodities. However, importantly, the irradiation of disinfestations of grain must be combined with good grain handling practices so that mycotoxin production can also be prevented during storage.

Concerning the direct action of irradiation on molds associated with foods and with feed, many reports are available in the literature that evaluate its effect, specifically on spices and on dried vegetables, which are the most irradiated food items worldwide. A study evaluating the effect of gamma-irradiation on the fungal load in red chillies was conducted by Iqbal and others (2013) and concluded that irradiation doses of $6 \mathrm{kGy}$ were sufficient to reduce the fungal load by 5 logs. Another study conducted on hot peppers observed reductions by 1 and 2 logs of the fungal load with doses of 2 and $4 \mathrm{kGy}$, respectively (Iqbal and others 2012). With a dose of $6 \mathrm{kGy}$, no molds were detected. Similarly, Legnani and others (2001) studied the effect of gamma-irradiation on the microbiological qualities of black pepper, red chili, oregano, rosemary, and sage. In this study, radiation doses of $5 \mathrm{kGy}$ were suitable to significantly reduce the load of molds (between $65 \%$ and $80 \%$ ); however, their complete elimination was only achieved with 10 kGy. In this case, Aspergillus niger, Cladosporium spp., Penicillium spp., and Rhizopus spp. were the most resistant to irradiation doses of $5 \mathrm{kGy}$. Similar results were obtained by Farag and others (1995) who studied the effect of irradiation on marjoram, ginger, and hot pepper. These authors reported the complete elimination of molds and, specifically, of Aspergillus flavus (a producer of AFs) with a radiation dose of $10 \mathrm{kGy}$. Coriander, cumin, turmeric, and chili were also submitted to irradiation experiments by Alam and others (1992) who obtained $D_{10}$ values for molds that ranged from 0.71 to $2.14 \mathrm{kGy}$, depending on the spice studied. In this case, an irradiation dose of $5 \mathrm{kGy}$ was considered sufficient to control fungal contamination because no molds were detected in samples after 3 and 6 mo of storage.

As can be observed from these studies, a substantial reduction of the fungal load in spices and in seasonings is only achievable with irradiation levels above $5 \mathrm{kGy}$. In this case, the high levels of irradiation does not seem to affect the quality of products because no losses of flavor compounds, changes in volatile oil compositions, and weakening of antioxidant properties at irradiation levels of $10 \mathrm{kGy}$ or even $30 \mathrm{kGy}$ were found by several researchers and reviewed by Alam and Abrahem (2010). Thus, the irradiation of spices is widely used as an excellent substitute to fumigation with gases, such as ethylene, propylene oxide, or methyl bromide, which leave chemical residues (for example, ethylene chlorohydrins and ethylene bromohydrin) that are suspected to be harmful. The dried nature of these products may be the factor that favors their greater resistance to the ionizing energy.

Concerning the irradiation of grains, pulses, and seeds, the inactivation of molds in rough rice and in wheat through gammairradiation was reported by Wang and Yu (2010). In wheat, an irradiation dose of $3 \mathrm{kGy}$ was sufficient to reduce the presence of Alternaria, Aspergillus, and Fusarium 10-fold. After irradiation, Penicillium and Rhizopus species were not detected. In rice, the irradiation dose required to obtain the same effect was $5 \mathrm{kGy}$. After irradiation, the detection of molds had not significantly changed during storage periods of 6 and 12 mo. Maity and others (2008; 2009) also evaluated the effect of gamma-irradiation on the fungal diversity of rice seeds during storage periods up to $12 \mathrm{mo}$. The growth of isolated fungi was completely inhibited during this period with a 3-kGy dose, and no change in the germination potential was noted with doses ranging from 2 to $4 \mathrm{kGy}$. Aziz and 
others (2006b) studied the effect of gamma-irradiation on wheat, barley, maize, and sorghum and reported that fungi were completely inhibited by a dose of $5 \mathrm{kGy}$. In this study, bacteria were more resistant to radiation than molds, leading the authors to conclude that a radiation dose of $10 \mathrm{kGy}$ was required to improve the total hygiene of grains. Furthermore, no significant alteration of their nutritional constituents was observed. In later study, Aziz and others (2007) assessed the control of Fusarium species on wheat, barley, and maize seeds. Fusarium spp. were completely inhibited at $4.0 \mathrm{kGy}$ on barley and at $6.0 \mathrm{kGy}$ on wheat and on maize. A 6-kGy dose could also completely inhibit the fungal population in several types of grains; however, $4.0 \mathrm{kGy}$ only reduced the fungal load by 4 logs (Aziz and others 2006a). Aziz and Moussa (2004) also verified that gamma-irradiation at a dose of $5 \mathrm{kGy}$ inactivated the growth of molds and subsequent mycotoxin formation in maize, chick-peas, and groundnut seeds. In contrast, in ground and whole maize, D'Ovidio and others (2007) found that radiation doses of 30 and $100 \mathrm{kGy}$, respectively, were required for the complete inactivation of Aspergillus spp., Penicillium spp., and Fusarium spp.; and a major reduction in the mold load was also observed with lower doses, at 10 and $30 \mathrm{kGy}$, respectively. This work did not agree with previous studies that also evaluated the effect of irradiation on maize. For example, Webb and others (1959) found that radiation doses between 2.5 and $10 \mathrm{kGy}$ were sufficient to prevent the growth of molds in maize during storage and that the required dose increased with maize moisture content. In this study, molds that required higher moisture levels to grow were also more resistant to gamma-radiation. Similarly, Ferreira-Castro and others (2007) reported that Fusarium verticillioides survival percentages on maize irradiated with 2,5 , and $10 \mathrm{kGy}$ were $36 \%, 6 \%$, and $0 \%$, respectively; thus, a $5-\mathrm{kGy}$ dose could substantially contribute to the avoidance of maize contamination with this species. A radiation dose of $1.5 \mathrm{kGy}$ was also found to reduce the maize fungal population by $90 \%$ and $99 \%$, depending on the maize moisture content, which was 35\% and 39\%, respectively, in this case (Poisson and others 1971).

The effect of irradiation on sesame seeds was studied by Akueche and others (2012). An irradiation dose of $3 \mathrm{kGy}$ inactivated $75 \%$ of molds present, and doses above $6 \mathrm{kGy}$ completely eliminated any fungal development. Cowpea bean grains were studied by Lima and others (2011). Irradiation has been shown to be an effective method to preserve this variety of bean for 6 mo. The results indicated that $A$. niger was eliminated with $1.0 \mathrm{kGy}$; Aspergillus ochraceus with $2.5 \mathrm{kGy}$, A. flavus with $5 \mathrm{kGy}$; and fungi from the genera Rhizopus, Penicillium, and Fusarium with a 10-kGy radiation dose. Lotus seed irradiation was studied by Bhat and others (2010). Irradiation with a 7.5-kGy dose substantially reduced fungal contamination, and a $10-\mathrm{kGy}$ dose completely eliminated fungi. In this case, contaminant yeasts were the most resistant to irradiation because some survived 10-kGy treatments. Kottapalli and others (2003) used electron-beam irradiation to reduce malting barley infection with Fusarium, observing that doses higher than 4 kGy effectively reduced the fungal infection without affecting its germination. Zeinab and others (2001) reported that a 6-kGy dose could completely inhibit the fungal population of Nigella sativa seeds (black cumin).

Concerning feed, gamma-irradiation was used, for example, to extend the shelf life of hydrated feed for fish farming without using preservatives (Kim and others 2012). A 5-kGy dose was sufficient to eliminate molds. Ribeiro and others (2009) studied the effect of gamma-radiation on the mycoflora of poultry feed. The total elimination of mold viability was observed at $8 \mathrm{kGy}$; however, Aspergillus parasiticus and A. flavus were the most resistant to irradiation, which may pose some safety concerns because these species are AF producers. Refai and others (1996) studied the elimination of $A$. ochraceus from poultry feed concentrate using gamma-radiation and concluded that a dose of $4 \mathrm{kGy}$ could completely inhibit this species and the production of OTA. Similarly, El-Far and others (1992) studied the inhibition of A. flavus in the poultry diet, reporting that no fungal growth and AF production was observed at a 6-kGy dose. In contrast, Paster and others (1991) reported that irradiation doses of 7 to $10 \mathrm{kGy}$ delayed fungal development, particularly in feed grains with low moisture content, but did not completely prevent the moldiness of this product.

Another application of irradiation technology focuses on the treatment of fresh fruits and vegetables to increase shelf life. Aziz and Moussa (2002) studied the effect of gamma-radiation on 10 different type of fruits refrigerated at $<10{ }^{\circ} \mathrm{C}$ for $28 \mathrm{~d}$. The initial viable mold population ranged from $4.8 \times 10^{4}$ to $6.8 \times 10^{5}$ $\mathrm{CFU} / \mathrm{g}$. When fruits were submitted to $1.5-$ and $3.5-\mathrm{kGy}$ doses, the initial mold population was reduced on average by 2 and 3 logs, respectively. Nonetheless, no studies were conducted to evaluate the quality and physicochemical parameters of the irradiated fruits. More recently, Mostafavi and others (2012) studied the influence of low--irradiation doses on apple preservation. The results demonstrated that the germination of spores from Penicillium expansum was completely inhibited with a $0.6-\mathrm{kGy}$ dose and that doses between 0.3 and $0.6 \mathrm{kGy}$, which were combined with storage at $1{ }^{\circ} \mathrm{C}$, could avoid the development of rot for 9 mo without significantly changing the phenolics content, antioxidant activity, firmness, weight loss, and total soluble solids of the treated apples. Ben-Arie and Barkai-Golan (1969) showed that the inactivation of P. expansum could also be achieved in pears using a treatment with hot water $\left(47^{\circ} \mathrm{C}\right.$ for $\left.7 \mathrm{~min}\right)$, followed by gamma-irradiation at $0.5 \mathrm{kGy}$. The same treatment did not prevent the rotting of fruits inoculated with Botrytis cinerea and with Alternaria tenuis; however, a delay in disease development was observed. Kim and others (2010) studied the effect of gamma-radiation on peach. A dose of $1 \mathrm{kGy}$ inactivated B. cinerea, P. expansum, Rhizopus stolonifer var. stolonifer, and Monilinia fructicola in peach pulp, and the calculated $D_{10}$ values for each species were $0.15,0.23,0.16$, and $0.16 \mathrm{kGy}$, respectively. El-Samahy and others (2000) studied the microbiological and chemical properties of irradiated mango. An increased reduction in the fungal population on mango fruits was observed with irradiation doses increasing from 0.5 to $1.5 \mathrm{kGy}$. The ideal treatment reported by the authors involved dipping mangos in hot water $\left(55^{\circ} \mathrm{C}\right.$ for $\left.5 \mathrm{~min}\right)$ and irradiating with $1 \mathrm{kGy}$. With these conditions, the ripening of mangos could be delayed for $50 \mathrm{~d}$ at $12{ }^{\circ} \mathrm{C}$ without significantly changing their nutritive and sensory properties. A similar treatment for tomatoes was found to reduce B. cinerea, R. stolonifer, and Alternaria alternata decay (Barkai-Golan and others 1993). In this case, a hot water dip at $50^{\circ} \mathrm{C}$ for 2 min and an irradiation of $1 \mathrm{kGy}$ were required. Nonetheless, the treatment caused a more rapid softening of fruits. The shelf life of strawberries could also be extended for 2 to $3 \mathrm{~d}$ with irradiation doses of 2 to $3 \mathrm{kGy}$ when preserved at $23{ }^{\circ} \mathrm{C}$ and for 4 to $8 \mathrm{~d}$ when preserved at $8{ }^{\circ} \mathrm{C}$ (Shibaba and others 1967). In this work, lethal doses for 2 different strains of $B$. cinerea were found at 9.7 and $5.4 \mathrm{kGy}$, showing that resistance to irradiation may vary within the same species. Under the same experimental conditions, lethal doses for Penicillium sp. and Aspergillus sp. were 2 to 2.5 and 4 kGy, respectively. Ladaniya and others (2003) studied the influence of gamma-radiation on citrus fruits and concluded that radiation treatments could not reduce the decay of these products. Positive 
effects were only observed in mandarins. In this case, Penicillium rot could be delayed with a radiation dose of $1.5 \mathrm{kGy}$, whereas no significant changes in fruit firmness and in juice content were observed. However, total soluble solids increased, whereas acidity and vitamin $\mathrm{C}$ content decreased. In oranges and in limes, radiation treatments considerably changed the texture and appearance of fruits. In fact, in the literature, the irradiation of citrus fruit resulted in injuries that led to the development of black buttons on the skin and, later, to the development of rot (Maxie and others 1964; O'Mahony and others 1985). Macfarlane and Roberts (1968) also concluded that irradiation is satisfactory for the disinfection of orange fly because the required doses are extremely low; however, this method is not feasible for mold control because of injury provoked by the high doses required. According to these authors, an irradiation dose of $0.3 \mathrm{kGy}$ should not be exceeded for citrus fruit treatment. A review of the impact of ionizing radiation on fruits and vegetables can be consulted for more information concerning the subject (Arvanitoyannis and others 2009).

Concerning dried fruits, the irradiation of peanuts was evaluated by de Camargo and others (2012) who concluded that an irradiation level of $5.2 \mathrm{kGy}$ was suitable to prevent the growth of aflatoxigenic fungi without significantly affecting their polyunsaturated fatty acid and polyphenol contents. This observation agreed with previous data from Chiou and others (1990), which proved that radiation levels of 2.5 and $5.0 \mathrm{kGy}$ were effective in retarding the growth of $A$. parasiticus and in reducing the native mold population of peanuts, respectively. Additionally, Hilmy and others (1995) reported that 3.0 and $5.0 \mathrm{kGy}$ could completely inhibit $A$. flavus growth on peanut and nutmeg meal, respectively. In contrast, Prado and others $(2006,2003)$ observed only a reduction in fungal infections on peanuts irradiated with $5 \mathrm{kGy}$ and its total elimination only with $10 \mathrm{kGy}$. The effect of gamma-irradiation on the quality of walnuts was also studied (Wilson-Kakashita and others 1995). The mold count in walnuts was significantly reduced with irradiation doses above $5 \mathrm{kGy}$, which were shown to be more effective then propylene oxide treatments. Walnut lipid contents did not changed with gamma-radiation treatments; however, a small decrease in iodine contents and an increase in peroxide values were observed. Similarly, Emam and others (1994) compared the irradiation of semidry date fruits with methyl bromide treatments and concluded that irradiation at $3 \mathrm{kGy}$ was more effective at inhibiting the growth of fungi, despite causing a significant loss in weights of dates.

Concerning the direct effect of ionizing radiation on fungal species, Ribeiro and others (2011) studied the effect of gammaradiation (at $2 \mathrm{kGy}$ ) on $A$. flavus and on $A$. ochraceus. Irradiated strains showed different color and slight differences on the sizes of stipes, metulae, and conidia compared with the same nonirradiated strains. The authors also observed that irradiated strains produced 2 times more mycotoxins than control strains. A similar effect was observed by other researchers. Irradiated strains of A. flavus, A. parasiticus, A. niger, and $A$. ochraceus also produced more $\mathrm{AFB}_{1}$ or OTA and then nonirradiated strains (Schindler and others 1980; Ribeiro and others 2009). However, this finding is not a consensus observation because other researchers reported the opposite response; for example, irradiated spores of $A$. parasiticus did not produce more $\mathrm{AFB}_{1}$ than nonirradiated spores on rice (Sharma and others 1990). In addition, it was also observed that the increase of mycotoxin production by irradiated spores was due to the reduction of spores' number, because serially diluted spores by 4 to 5 log produced also more mycotoxin (Sharma and others 1980). Even so, it is recommended that appropriate storage practices are implemented after the irradiation process to avoid the proliferation of toxigenic fungi and the associated production of mycotoxins.

Maity and others (2011) evaluated the effects of gammaradiation on fungi isolated from rice. The responses of individual cultures of $A$. alternata, A. flavus, Trichoderma viride, and Curvularia geniculata submitted to irradiation doses up to $4.2 \mathrm{kGy}$ were evaluated. The inactivation of fungal viability was achieved at 2 and $3 \mathrm{kGy}$ for $T$. viride and for A. flavus, respectively, and at 2.5 $\mathrm{kGy}$ for $A$. alternata and for $C$. geniculata. Additionally, the following major changes in fungal morphology were observed: a reduction in colony radial growth, a reduction in the germination tube length and diameter, and, in some cases, multigerm tube formation. Similarly, Saleh and others (1988) reported the gammaradiation doses required to inactivate some fungal species. In this case, dematiaceous fungi with melanized mycelia and conidia, such as Alternaria, Curvularia, and Cladosporium, were more resistant to gamma-radiation, and the reported inactivation doses were 11.5 to $13.9,17$ to 20 , and 6.0 to $6.5 \mathrm{kGy}$, respectively, for each of these fungi. In contrast, $A$. niger, Aspergillus fumigatus, $A$. parasiticus, Fusarium solani, and a Penicillium sp. were inactivated by doses of 1.7 to $2.5 \mathrm{kGy}$, and $A$. flavus was inactivated by doses of 2.5 to 3.0 kGy. The effect of gamma-radiation on $A$. flavus and on $A$. parasiticus was also studied by Kume and others (1989). In humid conditions, these authors obtained $\mathrm{D}_{10}$ values of approximately 0.27 to $0.29 \mathrm{kGy}$ for both species, whereas in dry conditions, the doses required to reduce the load by 1 log were almost double $(0.5$ to $0.6 \mathrm{kGy})$. This study showed that dry spores were more resistant to gamma-radiation. The same observation was also reported by other authors (Poisson and others 1971; Chang and Lee 1980; LebaiJuri and others 1995). Gumus and others (2008) studied 2 heat-resistant molds, A. fumigatus and Paecilomyces variotii, which were isolated from margarine. The average $D_{10}$ value obtained for $A$. fumigatus was $1.08 \mathrm{kGy}$, whereas this value was $0.59 \mathrm{kGy}$ for $P$. variotii. The complete inactivation of $P$. variotii was achieved with $5 \mathrm{kGy}$, whereas a 7-kGy dose was required for $A$. fumigatus. The radiation sensitivities of $A$. flavus, $A$. niger, a Penicillium sp., $B$. cinerea, and $R$. stolonifer were also evaluated by Chang and Lee (1980). Aspergillus flavus, A. niger, and Penicillium sp. presented a similar $D_{10}$ value $(0.3$ to $0.35 \mathrm{kGy}$ ), whereas $B$. cinerea and $R$. stolonifer showed $D_{10}$ values of 0.55 and $1.0 \mathrm{kGy}$, respectively. Malla and others (1967) reported that Penicillium viridicatum strains were more sensitive to gamma-radiation than strains of $A$. flavus. Their total inhibition was obtained with a dose of $2 \mathrm{kGy}$. The authors also found that spores of strains with 6-mo-old cultures were more susceptible to irradiation than 3-wk-old cultures. Aziz and Moussa (2004) reported $D_{10}$ values in saline solutions for $A$. alutaceus, $A$. flavus, and for F verticillioides of $0.36,0.52$, and 0.87 kGy, respectively. Similarly, Geweely and Nawar (2006) evaluated the effect of gamma-radiation on Alternaria tenuissima, B. cinerea, P. expansum, and Stemphylium botryosum, which are pathogenic to pears. B. cinerea and $P$. expansum were more radiosensitive, with complete inactivation by a $1.0-\mathrm{kGy}$ dose, whereas $A$. tenuissima and $S$. botryosum were only inactivated by a dose of $3.0 \mathrm{kGy}$. LebaiJuri and others (1995) reported $D_{10}$ values for many species that are pathogenic to plants. For Fusarium species, radiation doses required to reduce the load by $1 \log$ were between 0.31 to 0.71 kGy. The most radioresistant species was F. moniliforme, whereas F. oxysporum showed the greatest potential for recovery after irradiation. These species are known to produce several mycotoxins, and their resistance to irradiation may raise some concerns 
for fungal development after treatments if the radiation doses used are not sufficient to completely eliminate these species.

As we have observed, the radiosensitivity of a specific fungal species may be substantially different, depending on the works consulted. These differences may result from innumerous factors whose influence has not been as extensively studied as, for instance, the simple effect of radiation on the fungal load in specific food matrixes. Such factors may include the form of fungal contamination (mycelium or spores), the moisture contents of spores or commodities, the age of spores, the nature of the substrate on which radiation treatments are performed, the existence of periods of refrigeration or of heating before or after treatments, and the combinations of radiation with other technologies. These factors are summarized in Figure 3. In general, dried spores are considered more resistant to radiation, as we have already discussed; however, commodities with high-moisture contents may favor fungal recovery after irradiation if inactivation is not complete. The effectiveness of irradiation also depends on the age of the spores. Spores more than 1 mo old and less than 5 mo old were substantially more resistant to gamma-radiation (Poisson and others 1971). These authors also observed that radiosensitivity increased with moderate heating $\left(40\right.$ to $50{ }^{\circ} \mathrm{C}$ ) before irradiation and with fungicide treatments (Poisson and others 1971). When experiments were conducted in inert supports rather than on nutritive media, the radiosensitivity of spores was also higher. Münzner (1969) reported additional observations, namely, that the recovery of irradiated spores was favored on optimal nutritive media by optimal incubation temperatures and that actively growing cultures of the molds were more sensitive to radiation than older cultures. A substantial difference in radiosensitivity may also be observed, depending on the strains tested. For example, for 2 different $B$. cinerea strains, gamma-radiation lethal doses were extremely different (9.7 and 5.4 kGy) (Shibaba and others 1967). Thus, a comparison of the susceptibility of fungal species to irradiation should be performed with care because numerous factors may change their susceptibility, particularly when the irradiation of natural substrates is involved.

\section{Irradiation to control mycotoxins}

Because mycotoxins are highly toxic, it is imperative that their levels in food and in feed are reduced as low as technologically feasible. Ionizing radiation is one among many technologies that can contribute to this purpose. As we have observed, first, its action on mold viability contributes to the avoidance of fungal development and, consequently, to the production of mycotoxins in commodities. Second, because ionizing radiation can have a direct action on mycotoxins under specific conditions, contributing to their elimination, this subject has been widely investigated, particularly concerning $\mathrm{AFB}_{1}$. Nonetheless, the available literature is not always in agreement because some reports claim substantial reductions in some mycotoxins through the action of irradiation, whereas others claim that irradiation is not effective at all. Next, we will review the main achievements reported for this subject.

One of the first reports studied the effect of gamma-radiation on dried $\mathrm{AFB}_{1}$ and on $\mathrm{AFG}_{1}$ spotted on TLC silica plates and solubilized in phosphate solutions (Frank 1970). The authors observed that dried AFLs were extremely radioresistant, whereas in solution, AFLs were sensitive to irradiation doses of 1 and 2.5 kGy, with degradation of approximately $90 \%$. Later, Van Dyck and others (1982) studied the radiosensitivity of $\mathrm{AFB}_{1}$ in water solutions and showed that an identical irradiation dose could eliminate only $34 \%$ of the mycotoxin. Furthermore, the authors observed that increasing doses of radiation could destroy increasing amounts of $\mathrm{AFB}_{1}$ until its total destruction at $20 \mathrm{kGy}$. Using a test with Salmonella typhimurium TA 98, these authors also demonstrated that $\mathrm{AFB}_{1}$ mutagenicity decreased with increasing doses of gamma-radiation. Nonetheless, when the concentration of $\mathrm{AFB}_{1}$ was increased 50 times, the effect of gamma rays was substantially lower, indicating that the mycotoxin concentration is a determinant factor to achieve satisfactory elimination percentages. Similar observations were later reported by Mutluer and Erkoç (1987) who studied the effect of gamma-radiation on $\mathrm{AFB}_{1}$, $\mathrm{AFB}_{2}, \mathrm{AFG}_{1}$, and $\mathrm{AFG}_{2}$ in solutions of water/DMSO. $\mathrm{AFB}_{1}$ was the most radiosensitive, and $\mathrm{AFB}_{2}$ was the most resistant. Irradiation doses of 5, 10, and $20 \mathrm{kGy}$ were studied. $\mathrm{AFB}_{1}$ and $\mathrm{AFG}_{1}$ were almost completely eliminated at $5 \mathrm{kGy}$, retaining $5 \%$ and $10 \%$ in solution, respectively. In contrast, $90 \%$ of $\mathrm{AFB}_{2}$ and $77 \%$ of $\mathrm{AFG}_{2}$ were resistant to the same radiation dose. With 10 and $20 \mathrm{kGy}, \mathrm{AFB}_{1}$ could be completely eliminated; however, $\mathrm{AFG}_{1}$ was only completely eliminated with the $20-\mathrm{kGy}$ dose. Patel and others (1989) also used this approach and investigated the synergetic effects between hydrogen peroxide and gamma-radiation on the elimination of $\mathrm{AFB}_{1}$ in aqueous solutions. In the presence of $5 \% \mathrm{H}_{2} \mathrm{O}_{2}$, these authors observed that a 1-kGy dose could eliminate $50 \mu \mathrm{g}$ of $\mathrm{AFB}_{1}$ and that a 4-kGy dose could eliminate $100 \mu \mathrm{g}$. The mycotoxin mutagenicity was also completely lost with $4 \mathrm{kGy}$ in the presence of $5 \% \mathrm{H}_{2} \mathrm{O}_{2}$ using an Ames microsomal test with S. typhimurium TA100. Additionally, these authors confirmed that artificially contaminated groundnuts could be detoxified using this strategy because these authors observed reductions of $\mathrm{AFB}_{1}$ from 14 to $3 \mu \mathrm{g} / \mathrm{g}$ and from 6.3 to $1.7 \mu \mathrm{g} / \mathrm{g}$ in treated samples. Despite the observation that AFLs were degraded by gamma-radiation, no degradation products were identified, although their presence in samples was observed using TLC in some cases. Recently, Wang and others (2011) approached this subject using gamma-irradiated solutions of $\mathrm{AFB}_{1}$ in methanol/water. Twenty different radiolytic products were obtained; however, only 7 products were tentatively identified. Using the quantitative structure-activity relation, 6 of the 7 radiolytic products were considered less toxic than $\mathrm{AFB}_{1}$ because these products lost the double bond in the terminal furan ring, which is the determinant for AF toxicity. Using chicken embryos, the lethality of AFs was observed to decrease with increasing gamma-irradiation doses (Ogbadu and Bassir 1979).

As we have observed, $\mathrm{AFB}_{1}$ in solution can be effectively degraded and detoxified using gamma-radiation. Most likely, this degradation is mediated by the oxidative radicals that originated from water radiolysis because dried $\mathrm{AFB}_{1}$ is more resistant to radiation than $\mathrm{AFB}_{1}$ in solution (Frank 1970). This possibility can be a limiting factor when radiation is applied to food and to feed products with the purpose of eliminating mycotoxins. Thus, studies in real matrixes are required to evaluate the true effect of irradiation on mycotoxins.

Iqbal and others (2013) evaluated the effect of gamma-radiation on the reduction of AFLs in chillies and observed that levels of AFLs decreased with increasing irradiation doses $(2,4$, and $6 \mathrm{kGy})$. The highest reductions obtained ranged from $81 \%$ to $91 \%$ and were achieved with a $6 \mathrm{kGy}$ dose. In contrast, Akueche and others (2012) did not observe any consistent reduction of AFLs and of OTA on irradiated sesame seed grains at doses ranging from 3 to $12 \mathrm{kGy}$; however, these authors obtained the lowest mycotoxin level on grains irradiated with a $15-\mathrm{kGy}$ dose. Jalili and others (2012) also studied the effect of gamma-radiation on AFL and OTA contents on pepper. The tested doses ranged from 5 to $30 \mathrm{kGy}$. The greatest reductions in mycotoxin levels (35\% to 


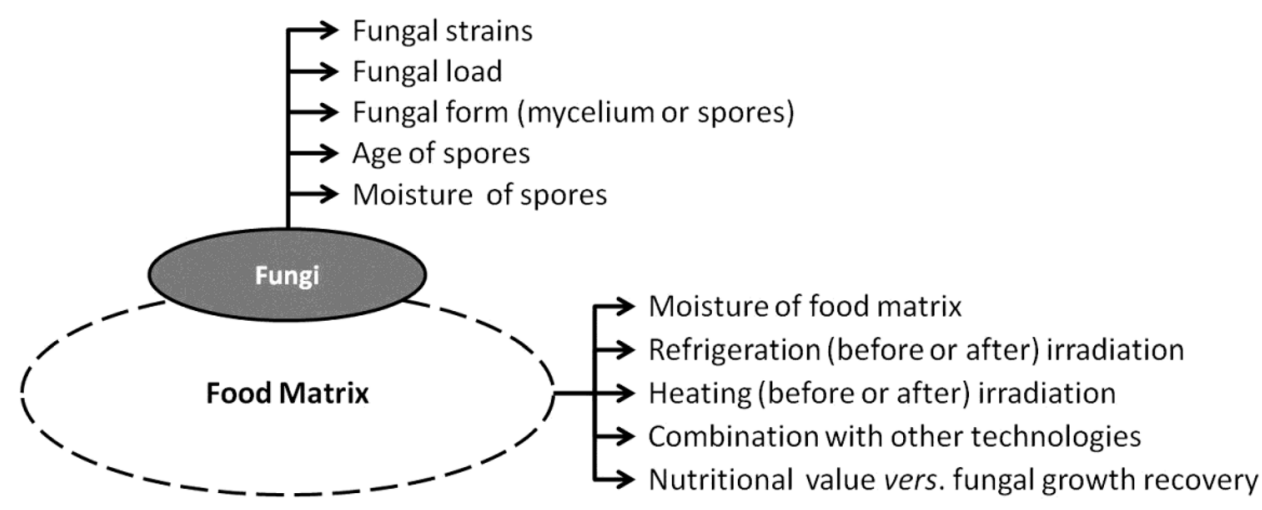

Figure 3-Factors that may influence the effectiveness of the spore irradiation process in food.

$55 \%$, depending on the mycotoxin) were observed in peppers with the highest moisture level (18\%) and were irradiated at $30 \mathrm{kGy}$. Authors also observed that $\mathrm{AFB}_{2}$ and $\mathrm{AFG}_{2}$ were more radioresistant than $\mathrm{AFB}_{1}$ and $\mathrm{AFG}_{1}$. OTA was the most radiosensitive. In contrast, Hooshmand and Klopfenstein (1995) did not verify any reduction in $\mathrm{AFB}_{1}$ in soybean, corn, and wheat irradiated with doses up to $20 \mathrm{kGy}$ at $9 \%, 13 \%$, or $17 \%$ moisture content, respectively. Nonetheless, these authors verified significant reductions in DON and ZEN concentrations at doses of 10 and $20 \mathrm{kGy}$, respectively, and in T-2 toxin with 7.5, 10, and $20 \mathrm{kGy}$ doses. With an irradiation dose of $10 \mathrm{kGy}$, the maximum allowable for food products, eliminations of $16 \%$ for $\mathrm{T}-2$ toxin in wheat, of $33 \%$ for DON in soybeans, and of $25 \%$ for ZEN in corn were observed, and with a $20-\mathrm{kGy}$ dose, reductions were $20 \%, 41 \%$, and $31 \%$, respectively. The elimination of AFLs from yellow maize and from peanuts using gamma-radiation was also studied (Farag and others 2004). The experiments conducted showed that gammaradiation at a dose of $20 \mathrm{kGy}$ could eliminate $76 \%$ of $\mathrm{AFB}_{1}$ in yellow maize and $85 \%$ of $\mathrm{AFB}_{1}$ in peanuts. Reductions of $83 \%$ to 97\% were also observed for the other AFLs at identical conditions. Prado and others (2003) also studied gamma-radiation effects on peanuts. Doses of 15 to $30 \mathrm{kGy}$ were sufficient to eliminate $\mathrm{AFB}_{1}$ by $55 \%$ to $74 \%$. Nonetheless, these authors did not observe any increased effect with increasing irradiation doses. In maize, Aquino and others (2005) observed that an irradiation dose of $10 \mathrm{kGy}$ could completely eliminate the presence of $\mathrm{AFB}_{1}$ and of $\mathrm{AFB}_{2}$ in samples. In contaminated feeds, Herzallah and others (2008) found that $\mathrm{AFB}_{1}$ and total AFL contents decreased by $43 \%$ and $40 \%$, respectively, with an irradiation dose of $25 \mathrm{kGy}$.

Most of the studies in the literature that reported on the impact of radiation on mycotoxins addressed AFs; however, studies with other mycotoxins can also be found, such as the effect of gammaradiation on patulin in apple juice concentrate (Zegota and others 1988). With up to a $2.5-\mathrm{kGy}$ dose, the elimination of patulin was partial and proportional to the irradiation doses. Beyond $2.5 \mathrm{kGy}$, patulin was completely eliminated. Similar results were obtained in an aqueous solution. At the tested conditions, irradiation did not change the titratable acidity, reducing sugars, carbonyl content, or amino acid composition of the juice. Yun and others (2008) corroborated this result in apple juice because these authors observed a reduction of $81 \%$ of patulin with a $3-\mathrm{kGy}$ dose and almost total elimination with $5 \mathrm{kGy}$. These researchers also investigated the effect of irradiation on patulin in water and observed that a 1-kGy dose was sufficient to completely eliminate patulin. Nonetheless, these authors also observed that organic acids, such as malic, lactic, or ascorbic acid, and amino acids, such as serine, threonine, or histidine, conferred a protective action on the radiolytic degradation of patulin.

Pure OTA, which was dissolved in methyl alcohol, was also tested and stable, even at $75 \mathrm{kGy}$ (Paster and others 1985). In contrast, OTA was sensitive to irradiation in water and in other aqueous solutions by Kostecki and others (1991), who reported that up to $50 \%$ of OTA was decomposed after gamma-irradiation. Similar results were obtained by Deberghes and others (1993), who reported that $50 \%$ of OTA in solution was also eliminated with doses of 2 and $3 \mathrm{kGy}$ and that the elimination percentage increased to $80 \%$ when 4 and $5 \mathrm{kGy}$ were used. Kumar and others (2012) irradiated OTA in powder form, in aqueous and methanolic solutions. In aqueous solution, $30 \%, 79 \%$, and $93 \%$ of the OTA were eliminated with doses of $1,2.5$, and $5 \mathrm{kGy}$, respectively. Nonetheless, OTA was more resistant to irradiation when dried or when in methanolic solution. With $10 \mathrm{kGy}$, only $24 \%$ of the OTA was eliminated in methanol, and almost none disappeared in the powder form. The total elimination of OTA in feedstuffs was achieved with irradiation doses of 15 and 20 kGy in yellow corn and in soybeans, respectively, but not in cottonseed cake and feed concentrates, for which the elimination reached only a maximum of $47 \%$ (Refai and others 1996). In green coffee beans, at a 10-kGy dose, OTA degradation increased with the moisture content of samples (Kumar and others 2012). Reductions of $5 \%, 9 \%, 20 \%, 90 \%$, and $100 \%$ in initial amounts of OTA were observed in coffee beans with moisture contents of $9 \%, 10 \%, 12 \%, 23 \%$, and $58 \%$, respectively.

The irradiation effect on DON and on 3-acetyl DON (3ADON) was tested by O'Neill and others (1993) on maize in aqueous solution and in the dry state. These authors found that both mycotoxins were more sensitive to irradiation when in aqueous solution than on maize. In aqueous solution, both mycotoxins were completely destroyed by $50 \mathrm{kGy}$, and their breakdown began at 1 and at $5 \mathrm{kGy}$ for DON and for 3-ADON, respectively. When irradiated on maize, breakdown only began after $20 \mathrm{kGy}$. In the dry condition, both mycotoxins were stable to irradiation at $50 \mathrm{kGy}$. Using electron bean irradiation, Stepanik and others (2007) also demonstrated a dose-dependent reduction of DON contents in wet distiller grains used as feed supplement. Reductions reached $47.5 \%$ to $75.5 \%$ at the highest doses (about $50 \mathrm{kGy}$ ). In contrast, the treatment of dry unprocessed wheat produced only a $17.6 \%$ reduction in the DON level at the highest dose, and the treatment was ineffective on dried distillers' grains. The effect of irradiation on Fusarium mycotoxins in wheat, flour, and bread 


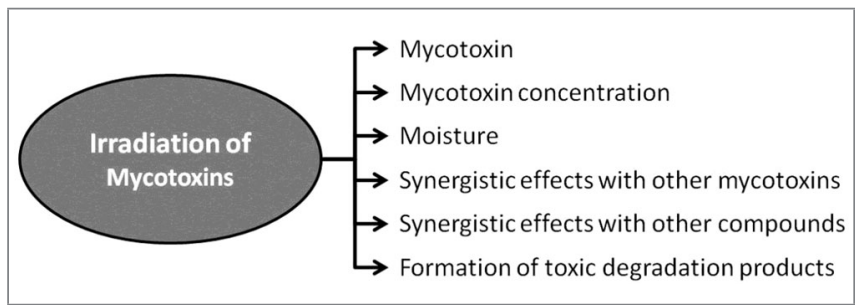

Figure 4-Factors that may influence the effectiveness of the mycotoxin irradiation process.

was also studied (Aziz and others 1997). DON, ZEN, and T-2 toxin concentrations were reduced with increasing doses of irradiation, but $\mathrm{T}-2$ toxin was the most resistant to radiation. All mycotoxins were completely eliminated with an $8-\mathrm{kGy}$ dose, and approximately $80 \%$ could be eliminated with a 6-kGy dose. Bread prepared from 6-kGy treated wheat flour was contaminated by DON, ZEN, and T-2 toxin with levels below $5 \mu \mathrm{g} / \mathrm{kg}$ of these mycotoxins (initial content was $272 \mu \mathrm{g} / \mathrm{kg}$ ).

Fumonisin $\mathrm{B}_{1}$ was also investigated. D'Ovidio and others (2007) studied the effect of irradiation on $\mathrm{FB}_{1}$ in aqueous solutions and in corn. $\mathrm{FB}_{1}$ in aqueous solutions was reduced by $99 \%$ using only $0.5 \mathrm{kGy}$; however, irradiation did not significantly reduce levels of this mycotoxin in whole and ground corn using irradiation doses up to $30 \mathrm{kGy}$. In contrast, Visconti and others (1996) reported that a $15-\mathrm{kGy}$ dose caused a decrease in fumonisin contents of approximately $20 \%$ in maize flour. Better elimination of $\mathrm{FB}_{1}$ was obtained by Aziz and others (2007) in wheat, maize, and barley grains, and the application on these grains of a radiation dose of $5 \mathrm{kGy}$ inactivated $\mathrm{FB}_{1}$ by $97 \%, 87 \%$, and $100 \%$, respectively. A dose of $7 \mathrm{kGy}$ was sufficient for the complete destruction of $\mathrm{FB}_{1}$ in wheat and maize.

In feedstuffs and feed samples, the influence of irradiation on Penicillium mycotoxins was studied by Aziz and Mattar (2007). Ten kGy eliminated citrinin contents up to $97.5 \%$ and eliminated OTA up to $78.5 \%$. Patulin, cyclopiazonic acid, and rubratoxin B were not detected after irradiating commodities with a 5.0-kGy dose. Considering the reviewed studies, in Figure 4, we summarize the factors that must be considered to apply the irradiation process to mycotoxins.

\section{Conclusions}

Although there are several contrasting reports regarding the effect of gamma rays on fungi and mycotoxins in different foods, gamma-irradiation can generally be considered to significantly improve the mycotoxicological safety of food and feed. Indeed, gamma-irradiation has an inhibitory effect on mycotoxigenic fungi, inhibiting or delaying their development and, consequently, the production of mycotoxins, and under appropriate conditions, gamma-irradiation can directly destroy mycotoxins. Nonetheless, irradiation should only be used in combination with good manufacturing and storage practices to prevent the proliferation of toxigenic fungi and the associated production of mycotoxins. Also important is that irradiation should never be used in commodities already molded or contaminated with mycotoxins with the intent of remediating the problem.

The following is a brief summary of main key points that may be drawn from the reviewed literature:

- The radiolytic process is influenced by many factors, such as absorbed doses, initial mycotoxin concentration or fungal load, the position in the irradiated system, the amount of moisture, and/or the presence of other matrix components.

- Radiosensitivity of fungi also depends on strain characteristics, mold forms (mycelium or spores), the moisture content of spores or commodities, spore age, commodity characteristics, the existence of periods of refrigeration or of heating before or after treatments, and on the combinations of radiation with other technologies. Fungi with melanized mycelia and spores are also more radioresistant than other structures. Commodities with higher moisture content may favor fungal recovery after irradiation if inactivation is not complete.

- The fungal load may be substantially reduced with irradiation levels of $5 \mathrm{kGy}$ and above; however, lower radiation doses can also be effective if products are previously treated with hot water.

- Irradiated fungal strains can occasionally produce more mycotoxins than original strains; however, appropriate storage after irradiation can minimize the development of remaining fungal propagules.

- Dried mycotoxins are extremely radioresistant, whereas in solution, mycotoxins are sensitive to irradiation. The oxidative radicals that originate from water radiolysis are responsible for their degradation.

- Combining gamma-irradiation with other treatments can improve the breakdown of mycotoxins (for example, using hydrogen peroxide, ammonium bicarbonate, or higher moisture conditions).

- Generally, more than $10-\mathrm{kGy}$ doses are required to eliminate a significant amount of mycotoxins in food matrixes. Patulin is an exception because patulin can be completely destroyed in apple juice by radiation doses between 2.5 and $5 \mathrm{kGy}$.

- The loss of toxicity after irradiation was only demonstrated for $\mathrm{AFB}_{1}$.

\section{Acknowledgments}

Thalita Calado and Luís Abrunhosa received support through grants SFRH/BD/79364/2011 and SFRH/BPD/43922/2008, respectively, from the Fundação para a Ciência e Tecnologia - FCT, Portugal. The authors also thank the FCT Strategic Project PEstOE/EQB/LA0023/2013 and the project "BioInd - Biotechnology and Bioengineering for Improved Industrial and Agro-Food processes, REF. NORTE-07-0124-FEDER-000028," which is cofunded by the Programa Operacional Regional do Norte $(\mathrm{ON}$. 2 - O Novo Norte), QREN, FEDER.

\section{References}

Akueche EC, Anjorin ST, Harcourt BI, Kana D, Adeboye E, Shehu I, Akande R, Adeleke AT, Shonowo OA, Adesanmi CA. 2012. Studies on fungal load, total aflatoxins and ochratoxin A contents of gamma-irradiated and non-irradiated Sesamum indicum grains from Abuja markets, Nigeria. Kasetsart J Nat Sci 46:371-82.

Alam KK, Abrahem M. 2010. Effect of irradiation on quality of spices. Intl Food Res J 17:825-36.

Alam MK, Choudhury N, Chowdhury NA, Youssouf QM. 1992.

Decontamination of spices by gamma radiation. Lett Appl Microbiol 14:199-202.

Aquino S, Ferreira F, Ribeiro DHB, Corrêa B, Greiner R, Villavicencio ALCH. 2005. Evaluation of viability of Aspergillus flavus and aflatoxins degradation in irradiated samples of maize. Braz J Microbiol 36:352-6.

Arvanitoyannis IS, Stratakos AC, Tsarouhas P. 2009. Irradiation applications in vegetables and fruits: a review. CRC Crit Rev Food Sci 49:427-62. Aziz NH, Attia ES, Farag SA. 1997. Effect of gamma-irradiation on the natural occurrence of Fusarium mycotoxins in wheat, flour and bread. Nahrung 41:34-7. 
Aziz NH, El-Far FM, Shahin AAM, Roushy SM. 2007. Control of Fusarium moulds and fumonisin $\mathrm{B}_{1}$ in seeds by gamma-irradiation. Food Control 18:1337-42

Aziz NH, Mahrous SR. 2004. Effect of gamma-irradiation on aflatoxin $\mathrm{B}_{1}$ production by Aspergillus flavus and chemical composition of three crop seeds. Nahrung 48:234-8.

Aziz NH, Mattar ZA. 2007. Influence of gamma-radiation on the occurrence of toxigenic Penicillium strains and mycotoxins production in different feedstuffs. Egypt J Biotechnol 25:130-44.

Aziz NH, Mattar ZA, Mahrous SR. 2006a. Contamination of grains by mycotoxin-producing molds and mycotoxins and control by gamma irradiation. J Food Saf 26:184-201.

Aziz NH, Moussa LAA. 2002. Influence of gamma-radiation on mycotoxin-producing moulds and mycotoxins in fruits. Food Control 13:281-8.

Aziz NH, Moussa LAA. 2004. Reduction of fungi and mycotoxins formation in seeds by gamma-radiation. J Food Saf 24:109-27.

Aziz NH, Souzan RM, Azza AS. 2006b. Effect of gamma-irradiation on the occurrence of pathogenic microorganisms and nutritive value of four principal cereal grains. Appl Radiat Isotopes 64:1555-62.

Barkai-Golan R, Padova R, Ross I, Lapidot M, Davidson H, Copel A. 1993. Combined hot water and radiation treatments to control decay of tomato fruits. Sci Hortic 56:101-5.

Ben-Arie R, Barkai-Golan R. 1969. Combined heat-radiation treatment to control storage rots of Spadona pears. Intl J Appl Radiat Isotopes 20: 687-90.

Bhat R, Sridhar KR, Karim AA. 2010. Microbial quality evaluation and effective decontamination of nutraceutically valued lotus seeds by electron beams and gamma irradiation. Radiat Phys Chem 79:976-81.

Bullerman LB, Bianchini A. 2007. Stability of mycotoxins during food processing. Intl J Food Microbiol 119:140-6.

Chang GH, Lee HB. 1980. Radiation sensitivity of some food decay fungi. Korean J Microbiol 18:1-6.

Chiou RY-Y, Lin CM, Shyu SL. 1990. Property characterization of peanut kernels subjected to gamma irradiation and its effect on the outgrowth and aflatoxin production by Aspergillus parasiticus. J Food Sci 55:210-3.

Codex. 2003a. Codex Alimentarius code of practice for radiation processing of food (CAC/RCP 19-1979, Rev.2-2003. Editorial correction 2011). CODEX Alimentarius Commission/FAO/WHO, Rome, Italy.

Codex. 2003b. Codex Alimentarius general standard for irradiated foods (Codex Standard 106-1983, Rev.1-2003). CODEX Alimentarius Commission/FAO/WHO, Rome, Italy.

D'Ovidio KL, Trucksess MW, Devries JW, Bean G. 2007. Effects of irradiation on fungi and fumonisin $\mathrm{B}_{1}$ in corn, and of microwave-popping on fumonisins in popcorn. Food Addit Contam 24:735-43.

de Camargo AC, Vieira TMFD, Regitano-d'Arce MAB, de Alencar SM, Calori-Domingues MA, Spoto MHF, Canniatti-Brazaca SG. 2012. Gamma irradiation of in-shell and blanched peanuts protects against mycotoxic fungi and retains their nutraceutical components during long-term storage. Intl J Mol Sci 13:10935-58.

de Campos SX, Sanches SM, Falone SZ, Vieira EM. 2004. Influence of rate dose in the degradation of the 2,4 dichlorophenoxyacetic acid (2,4-D) herbicide in water and methanol by gamma radiation from cobalt- 60 . Eclética Química 29:41-6.

Deberghes P, Deffieux G, Gharbi A, Betbeder AM, Boisard F, Blanc R, Delaby JF, Creppy EE. 1993. Détoxification de l'ochratoxine a par des moyens physique, chimique et enzymatiques. In: Creppy EE, Castegnaro M, Dirheimer G, editors. Human ochratoxicosis and its pathologies. Paris, France: John Libbey Eurotext Ltd. p 75-82.

EC. 2003. Revision of the opinion of the Scientific Committee on Food on the irradiation of food (SCF/CS/NF/IRR/24 Final). European Commission Health and Consumer Protection Directorate-General, Brussels, Belgium.

El-Far F, Aziz NH, Hegazy S. 1992. Inhibition by gamma-irradiation and antimicrobial food additives of aflatoxin $\mathrm{B}_{1}$ production by Aspergillus flavus in poultry diet. Nahrung 36:143-9.

El-Samahy SK, Youssef BM, Askar AA, Swailam HMM. 2000.

Microbiological and chemical properties of irradiated mango. J Food Saf 20:139-56.

Emam OA, Farag SEA, Hammad AI. 1994. Comparative studies between fumigation and irradiation of semidry date fruits. Nahrung 38:612-20.

EU. 1999a. Directive 1999/2/EC of the European Parliament and of the Council of 22 February 1999 on the approximation of the laws of the
Member States concerning foods and food ingredients treated with ionising radiation. Off J Eur Communities L66/16-L66/22.

EU. 1999b. Directive 1999/3/EC of the European Parliament and of the Council of 22 February 1999 on the establishment of a Community list of foods and food ingredients treated with ionising radiation. Off J Eur Communities L66/24-L66/25.

EU. 2009. List of Member States' authorisations of food and food ingredient which may be treated with ionising radiation. Off J Eur Commun C283/5.

FAO/IAEA/WHO. 1981. Wholesomeness of irradiated food. Technical Report Series 659. Geneva, Switzerland: Joint FAO/IAEA/WHO Expert Committee.

FAO/IAEA/WHO. 1999. High-dose irradiation: wholesomeness of food irradiated with doses above $10 \mathrm{kGy}$. Report of a Joint FAO/IAEA/WHO study group. World Health Organization technical report series 890:1-197.

Farag RS, El-Baroty GS, Abo-Hagger AA. 2004. Aflatoxin destruction and residual toxicity of contaminated-irradiated yellow corn and peanuts on rats. Adv Food Sci 26:122-9.

Farag SE-DA, Aziz NH, Attia E-SA. 1995. Effect of irradiation on the microbiological status and flavouring materials of selected spices. Z Lebensm Unters Forsch 201:283-8.

Farkas J. 1989. Microbiological safety of irradiated foods. Intl J Food Microbiol 9:1-15.

Farkas J. 1998. Irradiation as a method for decontaminating food: a review. Intl J Food Microbiol 44:189-204.

Farkas J. 2006. Irradiation for better foods. Trends Food Sci Technol 17:148-52.

Farkas J, Mohácsi-Farkas C. 2011. History and future of food irradiation. Trends Food Sci Technol 22:121-6.

Ferreira-Castro FL, Aquino S, Greiner R, Ribeiro DHB, Reis TA, Corrêa B. 2007. Effects of gamma radiation on maize samples contaminated with Fusarium verticillioides. Appl Radiat Isotopes 65:927-33.

Ferrier P. 2010. Irradiation as a quarantine treatment. Food Policy 35:548-55 Foroud NA, Eudes F. 2009. Trichothecenes in cereal grains. Intl J Mol Sci 10:147-73.

Frank HK. 1970. Radiation resistance of aflatoxins. Irradiat Aliments 11:15-20.

Geweely NSI, Nawar LS. 2006. Sensitivity to gamma irradiation of post-harvest pathogens of pear. Intl J Agric Biol 8:710-6.

Gumus T, Gecgel U, Demirci AS, Arici M. 2008. Effects of gamma irradiation on two heat-resistant moulds: Aspergillus fumigatus and Paecilomyces variotii isolated from margarine. Radiat Phys Chem 77:680-3.

Herzallah S, Alshawabkeh K, Al Fataftah A. 2008. Aflatoxin decontamination of artificially contaminated feeds by sunlight, gamma-radiation, and microwave heating. J Appl Poultry Res 17:515-21.

Hilmy N, Chosdu R, Matsuyama A. 1995. The effect of humidity after gamma-irradiation on aflatoxin $\mathrm{B}_{1}$ production of $A$. flavus in ground nutmeg and peanut. Radiat Phys Chem 46:705-11.

Hooshmand H, Klopfenstein CF. 1995. Effects of gamma irradiation on mycotoxin disappearance and amino acid contents of corn, wheat, and soybeans with different moisture contents. Plant Foods Hum Nutr 47:227-38

Iqbal Q, Amjad M, Asi MR, Arino A. 2012. Mold and aflatoxin reduction by gamma radiation of packed hot peppers and their evolution during storage. J Food Prot 75:1528-31.

Iqbal SZ, Bhatti IA, Asi MR, Zuber M, Shahid M, Parveen I. 2013. Effect of $\gamma$-irradiation on fungal load and aflatoxins reduction in red chillies. Radiat Phys Chem 82:80-4.

Jalili M, Jinap S, Noranizan MA. 2012. Aflatoxins and ochratoxin A reduction in black and white pepper by gamma radiation. Radiat Phys Chem 81:1786-8.

Jørgensen K. 2005. Occurrence of ochratoxin A in commodities and processed food: a review of EU occurrence data. Food Addit Contam 22:26-30

Jouany JP. 2007. Methods for preventing, decontaminating and minimizing the toxicity of mycotoxins in feeds. Anim Feed Sci Technol 137:342-62.

Kim D, Song H, Lim S, Jo M, Song D, Jo C. 2012. Shelf-life extension of preservative-free hydrated feed using gamma pasteurization and its effect on growth performance of eel. Radiat Phys Chem 81:1095-7.

Kim KH, Kim MS, Kim HG, Yook HS. 2010. Inactivation of contaminated fungi and antioxidant effects of peach (Prunus persica L. Batsch cv Dangeumdo) by $0.5-2 \mathrm{kGy}$ gamma irradiation. Radiat Phys Chem 79:495-501. 
Kostecki M, Golinski P, Uchman W, Grabarkiewicz-Szczesna J. 1991. Decomposition of ochratoxin A by heat and gamma-irradiation. IARC Sci Publ 109-11.

Kottapalli B, Wolf-Hall CE, Schwarz P, Schwarz J, Gillespie J. 2003. Evaluation of hot water and electron beam irradiation for reducing Fusarium infection in malting barley. J Food Prot 66:1241-6.

Kumar S, Kunwar A, Gautam S, Sharma A. 2012. Inactivation of A. ochraceus spores and detoxification of ochratoxin A in coffee beans by gamma irradiation. J Food Sci 77:T44-T51.

Kume T, Furuta M, Todoriki S, Uenoyama N, Kobayashi Y. 2009. Status of food irradiation in the world. Radiat Phys Chem 78:222-6.

Kume T, Ito H, Soedarman H, Ishigaki I. 1989. Radiosensitivity of toxigenic Aspergillus isolated from spices and destruction of aflatoxins by gamma-irradiation. Radiat Phys Chem 34:973-8.

Ladaniya MS, Singh S, Wadhawan AK. 2003. Response of 'Nagpur' mandarin, 'Mosambi' sweet orange and 'Kagzi' acid lime to gamma radiation. Radiat Phys Chem 67:665-75.

Lado BH, Yousef AE. 2002. Alternative food-preservation technologies: efficacy and mechanisms. Microb Infect 4:433-40.

Le Caër S. 2011. Water radiolysis: influence of oxide surfaces on $\mathrm{H}_{2}$ production under ionizing radiation. Water 3:253.

LebaiJuri M, Omar M, Yusof N. 1995. Sensitivity of the conidia of plant pathogenic fungi to gamma-rays, electron particles and X-ray (Bremsstrahlung) irradiation. World J Microbiol Biotechnol 11:610-4.

Legnani PP, Leoni E, Righi F, Zarabini LA. 2001. Effect of microwave heating and gamma irradiation on microbiological quality of spices and herbs. Ital J Food Sci 13:337-45.

Lima KdSC, Souza LB, Godoy RLdO, França TCC, Lima ALdS. 2011. Effect of gamma irradiation and cooking on cowpea bean grains (Vigna unguiculata L. Walp). Radiat Phys Chem 80:983-9.

Macfarlane JJ, Roberts EA. 1968. Some effects of gamma radiation on Washington navel and Valencia oranges. Aust J Exp Agric 8:625-9.

Maity JP, Chakraborty A, Chanda S, Santra SC. 2008. Effect of gamma radiation on growth and survival of common seed-borne fungi in India. Radiat Phys Chem 77:907-12.

Maity JP, Kar S, Banerjee S, Chakraborty A, Santra SC. 2009. Effects of gamma irradiation on long-storage seeds of Oryza sativa (cv. 2233) and their surface infecting fungal diversity. Radiat Phys Chem 78:1006-10.

Maity JP, Kar S, Banerjee S, Sudershan M, Chakraborty A, Santra SC. 2011. Effects of gamma radiation on fungi-infected rice (in vitro). Intl J Radiat Biol 87:1097-102.

Malla DS, Diehl JF, Salunkhe DK. 1967. In vitro susceptibility of strains of Penicillium viridicatum and Aspergillus flavus to $\gamma$-irradiation. Experientia 23:492-3.

Maxie EC, Eaks IL, Sommer NF. 1964. Some physiological effects of gamma irradiation on lemon fruit. Radiat Bot 4:405-11.

Moake MM, Padilla-Zakour OI, Worobo RW. 2005. Comprehensive review of patulin control methods in foods. Compr Rev Food Sci Food Saf 4:8-21. Mostafavi HA, Mirmajlessi SM, Mirjalili SM, Fathollahi H, Askari H. 2012. Gamma radiation effects on physico-chemical parameters of apple fruit during commercial post-harvest preservation. Radiat Phys Chem 81:666-71.

Münzner R. 1969. Some factors affecting the radiosensitivity of moulds. Arch Mikrobiol 64:349-56.

Mutluer B, Erkoc FU. 1987. Effects of gamma irradiation on aflatoxins. Z Lebensm Unters Forsch 185:398-401.

O’Mahony M, Wong SY, Odbert N. 1985. Sensory evaluation of navel oranges treated with low doses of gamma-radiation. J Food Sci 50:639-46.

O'Neill K, Damoglou AP, Patterson MF. 1993. The stability of deoxynivalenol and 3-acetyl deoxynivalenol to gamma irradiation. Food Addit Contam 10:209-15.

Ogbadu G, Bassir O. 1979. Toxicological study of $\gamma$-irradiated aflatoxins using the chicken embryo. Toxicol Appl Pharmacol 51:379-82.

Paster N, Barkaigolan R, Padova R. 1985. Effect of gamma-radiation on ochratoxin production by the fungus Aspergillus ochraceus. J Sci Food Agric 36:445-9.

Paster N, Bartov I, Menasherov M, Padova R, Ross I. 1991. Efficacy of gamma-irradiation in preventing moldiness and preserving the nutritional-value of corn grain for broiler chicks. Poultry Sci 70:823-9.

Patel UD, Govindarajan P, Dave PJ. 1989. Inactivation of aflatoxin $B_{1}$ by using the synergistic effect of hydrogen peroxide and gamma radiation. Appl Environ Microbiol 55:465-7.
Paterson RR, Lima N. 2010. Toxicology of mycotoxins. In: Luch A, editor. Molecular, clinical and environmental toxicology. 100 ed. Berlin, Germany: Birkhauser Verlag. p 31-63.

Peraica M, Radic B, Lucic A, Pavlovic M. 1999. Toxic effects of mycotoxins in humans. Bull World Health Organ 77:754-66.

Pfohl-Leszkowicz A, Manderville RA. 2007. Ochratoxin A: an overview on toxicity and carcinogenicity in animals and humans. Mol Nutr Food Res 51:61-99.

Poisson J, Cahagnier B, Guilbot A. 1971. On the gamma ray sensitivity of the main corn moulds conidia. Incidence on the radurisation of corn. Mycopath Mycol Appl 45:193-209.

Prado G. 2005. Gamma-irradiation effect $\left({ }^{60} \mathrm{Co}\right)$ in fungi frequency of peanut in natura and after storage. Lavras, Minas Gerais, Brasil: Universidade Federal de Lavras.

Prado G, de Carvalho EP, Madeira JEGC, Morais VAD, de Oliveira MS, Correa RF, Cardoso VN. 2006. Gamma-irradiation effect $\left({ }^{60} \mathrm{Co}\right)$ in fungi frequency of peanut in natura and after storage. Cienc Agrotec 30: 930-6.

Prado G, de Carvalho EP, Oliveira MS, Madeira JGC, Morais VD, Correa RF, Cardoso VN, Soares TV, da Silva JFM, Goncalves RCP. 2003. Effect of gamma irradiation on the inactivation of aflatoxin $\mathrm{B}_{1}$ and fungal flora in peanut. Braz J Microbiol 34:138-40.

Refai MK, Aziz NH, ElFar F, Hassan AA. 1996. Detection of ochratoxin produced by $A$. ochraceus in feedstuffs and its control by gamma radiation. Appl Radiat Isotopes 47:617-21.

Ribeiro J, Cavaglieri L, Vital H, Cristofolini A, Merkis C, Astoreca A, Orlando J, Caru M, Dalcero A, Rosa CAR. 2011. Effect of gamma radiation on Aspergillus flavus and Aspergillus ochraceus ultrastructure and mycotoxin production. Radiat Phys Chem 80:658-63.

Ribeiro JMM, Cavaglieri LR, Vital HD, Kruger CD, Rosa CAD. 2009. Gamma radiation on the mycoflora of poultry feed and Aspergillus species. Cien Rural 39:1452-8.

Saleh YG, Mayo MS, Ahearn DG. 1988. Resistance of some common fungi to gamma irradiation. Appl Environ Microbiol 54:2134-5.

Satin M. 1996. Food irradiation - a guidebook. 2nd ed. Lankaster:

Technomic Publishing Company.

Schindler AF, Abadie AN, Simpson RE. 1980. Enhanced aflatoxin production by Aspergillus flavus and Aspergillus parasiticus after gamma-irradiation of the spore inoculum. J Food Prot 43:7-9.

Sharma A, Behere AG, Padwal-Desai SR, Nadkarni GB. 1980. Influence of inoculum size of Aspergillus parasiticus spores on aflatoxin production. Appl Environ Microbiol 40:989-93.

Sharma A, Padwal-Desai SR, Nair PM. 1990. Aflatoxin-producing ability of spores of Aspergillus parasiticus exposed to gamma radiation. J Food Sci $55: 275-6$.

Shea KM. 2000. Technical report: irradiation of food. Pediatrics 106:1505-10.

Shibaba S, Ito H, Iizuka H. 1967. Effect of gamma irradiation on strawberries as a means of extending its shelf-life and lethal dose of Botrytis cinerea. Agric Biol Chem 31:930-4.

Stefanova R, Vasilev NV, Spassov SL. 2010. Irradiation of food, current legislation framework, and detection of irradiated foods. Food Anal Method 3:225-52.

Stepanik T, Kost D, Nowicki T, Gaba D. 2007. Effects of electron beam irradiation on deoxynivalenol levels in distillers' dried grain and solubles and in production intermediates. Food Addit Contam 24:1001-6.

Stoev SD. 2013. Food safety and increasing hazard of mycotoxin occurrence in foods and feeds. Crit Rev Food Sci Nutr 53:887-901.

Van Dyck PJ, Tobback P, Feyes M, van de Voorde H. 1982. Sensitivity of aflatoxin $\mathrm{B}_{1}$ to ionizing radiation. Appl Environ Microbiol 43:1317-9. van Egmond HP, Schothorst RC, Jonker MA. 2007. Regulations relating to mycotoxins in food. Anal Bioanal Chem 389:147-57.

Variyar PS, Chatterjee S, Sajilata MG, Singhal RS, Sharma A. 2008. Natural existence of 2-alkylcyclobutanones. J Agric Food Chem 56:11817-23.

Visconti A, Solfrizzo M, Doko MB, Boenke A, Pascale M. 1996. Stability of fumonisins at different storage periods and temperatures in gamma-irradiated maize. Food Addit Contam 13:929-38.

Voss KA, Smith GW, Haschek WM. 2007. Fumonisins: Toxicokinetics, mechanism of action and toxicity. Anim Feed Sci Technol 137:299-325.

Wang F, Xie F, Xue XF, Wang ZD, Fan B, Ha YM. 2011. Structure elucidation and toxicity analyses of the radiolytic products of aflatoxin $B_{1}$ in methanol-water solution. J Hazard Mater 192:1192-202. 
Wang J, Yu Y. 2010. Inactivation of mildew in rough rice and wheat by gamma irradiation. Radiat Phys Chem 79:740-3.

Webb BD, Thiers HD, Richardson LR. 1959. Studies in feed spoilage: inhibition of mold growth by gamma radiation. Appl Microbiol 7:32933.

Williams JH, Phillips TD, Jolly PE, Stiles JK, Jolly CM, Aggarwal D. 2004. Human aflatoxicosis in developing countries: a review of toxicology, exposure, potential health consequences, and interventions. Am J Clin Nutr 80:1106-22.

Wilson-Kakashita G, Gerdes DL, Hall WR. 1995. The effect of gamma irradiation on the quality of English walnuts (Juglans regia). LWT-Food Sci Technol 28:17-20.

Wood OB, Bruhn CM. 2000. Position of the American Dietetic Association: food irradiation. J Am Diet Assoc 100:246-53.
Yun H, Lim S, Jo C, Chung J, Kim S, Kwon JH, Kim D. 2008. Effects of organic acids, amino acids and ethanol on the radio-degradation of patulin in an aqueous model system. Radiat Phys Chem 77:830-4.

Zegota H, Zegota A, Bachman S. 1988. Effect of irradiation on the patulin content and chemical composition of apple juice concentrate. Z Lebensm Unters Forsch 187:235-8.

Zeinab EMEB, Hala AF, Mohie EDZEF, Seham YMET. 2001. Inhibitory effect of gamma radiation and Nigella sativa seeds oil on growth, spore germination and toxin production of fungi. Radiat Phys Chem 60: 181-9.

Zinedine A, Soriano JM, Moltó JC, Mañes J. 2007. Review on the toxicity, occurrence, metabolism, detoxification, regulations and intake of zearalenone: an oestrogenic mycotoxin. Food Chem Toxicol 45:1-18. 